\title{
Corrigendum: Mechanism of Rhinovirus Immunity and Asthma
}

\author{
Zuqin Yang ${ }^{1 \dagger}$, Hannah Mitländer ${ }^{1 \dagger}$, Tytti Vuorinen ${ }^{2}$ and Susetta Finotto ${ }^{1 *}$ \\ 1 Department of Molecular Pneumology, Friedrich-Alexander-Universität (FAU) Erlangen-Nürnberg, Universitätsklinikum \\ Erlangen, Erlangen, Germany, ${ }^{2}$ Medical Microbiology, Turku University Hospital, Institut of Biomedicine, University of Turku, \\ Turku, Finland
}

Keywords: asthma, rhinovirus, host defense, immune evasion, interferon type I

\section{A Corrigendum on}

Mechanism of Rhinovirus Immunity and Asthma

By Yang Z, Mitländer H, Vuorinen T and Finotto S (2021). Front. Immunol. 12:731846. doi: 10.3389/fimmu.2021.731846

\section{OPEN ACCESS}

Approved by:

Frontiers Editorial Office,

Frontiers Media SA, Switzerland

*Correspondence:

Susetta Finotto susetta.finotto@uk-erlangen.de

${ }^{\text {t}}$ These authors have contributed equally to this work

Specialty section: This article was submitted to Cytokines and Soluble Mediators in Immunity, a section of the journal Frontiers in Immunology

Received: 22 October 2021 Accepted: 02 November 2021 Published: 16 November 2021

Citation:

Yang Z, Mitländer $\mathrm{H}$, Vuorinen T and Finotto S (2021) Corrigendum: Mechanism of Rhinovirus Immunity and Asthma.

Front. Immunol. 12:800020. doi: 10.3389/fimmu.2021.800020
In the original article, the authors neglected to include the funder Collaborative Research Centre (CRC) 1181 (Erlangen), grant number TP-B08 $\mathrm{N}$ to authors Zuqin Yang and Susetta Finotto.

In the original article, there was an error. The scientific meaning of the following sentence was unclear owing to poor syntax: "In asthma, are predominantly induced ILC2 producing type 2 cytokine IL-4, IL-5, IL-13, and IL-9".

A correction has been made to Innate Immune Response in Asthma, Innate Lymphoid Cells (ILC2), Paragraph 1. The sentence should read: "In asthma, ILC2 producing type 2 cytokine IL-4, IL-5, IL-13, and IL-9 are predominantly induced".

The same is true of the following sentence: "After RV16 infection, in Tregs were induced both in healthy control and asthmatic subjects with upregulated anti-viral gene expression, such as IFI44L, MX1, ISG15, IRF and STAT1".

A correction has been made to Adaptive Immune Response in Asthma, Treg, Paragraph 2. The sentence should read: "After RV16 infection, Tregs were induced both in healthy control and asthmatic subjects with upregulated anti-viral gene expression, such as IFI44L, MX1, ISG15, IRF and STAT1".

The authors apologize for these errors and state that they do not change the scientific conclusions of the article in any way. The original article has been updated.

\footnotetext{
Publisher's Note: All claims expressed in this article are solely those of the authors and do not necessarily represent those of their affiliated organizations, or those of the publisher, the editors and the reviewers. Any product that may be evaluated in this article, or claim that may be made by its manufacturer, is not guaranteed or endorsed by the publisher.

Copyright (๑) 2021 Yang, Mitländer, Vuorinen and Finotto. This is an open-access article distributed under the terms of the Creative Commons Attribution License (CC BY). The use, distribution or reproduction in other forums is permitted, provided the original author(s) and the copyright owner(s) are credited and that the original publication in this journal is cited, in accordance with accepted academic practice. No use, distribution or reproduction is permitted which does not comply with these terms.
} 